\title{
Renovación ética del marxismo y rigor analítico
} Luis Villoro

\author{
Paulette Dieterlen, Marxismo analítico: explicaciones \\ funcionales e intenciones. México, UNAM, 1995, 256 pp.
}

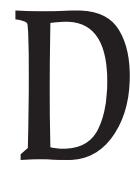

espués de la caída de los regímenes del "socialismo real", muchos se apresuraron a decretar el deceso del pensamiento marxista. Pero la situación está lejos de ser tan simple. Quizá estemos ante una paradoja.

La filosofía no es una doctrina, sino una actividad crítica, que pone en cuestión el pensamiento convencional. Cuando esa actividad se fija en una doctrina que pretende dar respuestas definitivas, se anquilosa y pierde su capacidad crítica. De ser una inquisición permanente, inconforme con cualquier pensamiento establecido, pasa a ser una forma más de pensamiento establecido. Entonces puede ser utilizada para consolidar un poder. De filosofía se convierte en ideología. Ese fue el destino del marxismo. El pensamiento de Marx era una crítica radical de toda ideología, una invitación a poner en cuestión muchas ideas recibidas. Cuando los intereses de un poder político lo convierten en una ideología más a su servicio, corre el peligro de dejar de ser una actividad filosófica genuina.

En cambio, cuando con la caída del llamado "socialismo real" la exigencia de servir a un poder político desaparece, el pensamiento marxista puede volver a considerarse en lo que tiene de actividad filosófica genuina y separarse de su utilización ideológica. Entonces puede dar lugar a una discusión de sus propuestas teóricas, a la luz de las controversias filosóficas vivas en otras corrientes de pensamiento. El marxismo puede recuperarse así como una reflexión viva. Pero para ello ha tenido que pagar un precio: al perderse como ideología, deja de funcionar también como un motor racional de la acción hacia fines políticos concretos. Esto es lo que sucede en el llamado "marxismo analítico", algunos de cuyos temas centrales expone y discute el libro que comentamos.

Un problema vertebral de la filosofía marxista -en mi opinión- fue su divi- 
sión entre dos posiciones difícilmente compatibles. Por una parte, estaba su cientificismo. Frente a las doctrinas sociales anteriores, se presentaba como una ciencia de tipo causal. Fue ya la opinión de Engels y se reforzó en la mayoría de las interpretaciones posteriores. Kautsky -el teórico más importante de la socialdemocracia alemana- veía en el marxismo una doctrina científica destinada a establecer las leyes generales del desarrollo histórico; sólo gracias a esa ciencia, incorporada al proletariado, podría éste liberarse. Pese a su oposición radical a la socialdemocracia alemana, Lenin y sus discípulos coincidieron con la posición de Kautsky en ese punto preciso. El "marxismo-leninismo", en sus distintas formulaciones, pretendía ser una ciencia cabal de las leyes de la historia. Lucio Coletti resumía así esta idea:

En tanto doctrina científica el marxismo consiste esencialmente en el descubrimiento de relaciones objetivas de causalidad. Dilucida las leyes que rigen el sistema, describe las contradicciones que lo minan desde el interior y que marcan su destino. ${ }^{1}$

Sin embargo, el marxismo es también una teoría de la acción social, que proyecta una sociedad más justa y exhorta a realizarla. En ese sentido, propone valores, y muchos percibieron en él un alto contenido moral. Pretendía, en efecto, liberarnos de la enajenación y hacer posible una sociedad verdaderamente humana. Así, a la vez que se presentaba como una teoría científica causal, era también una propuesta de acción social dirigida por fines éticos. Por eso, al lado de la corriente "cientificista", predominante tanto en la socialdemocracia alemana como en el "marxismo-leninismo" soviético, encontramos también la interpretación del marxismo como una "filosofía de la praxis", en autores como Antonio Gramsci en Italia o Adolfo Sánchez Vázquez en México.

En mi opinión, la coexistencia en el marxismo de esas dos posiciones fue en gran medida responsable de su éxito. ¿Qué podíamos pedir mejor que una ciencia rigurosa que desemboca en una propuesta de acción y una postura ética fundada en una ciencia? El marxismo prometía a la vez una transformación social profunda y un conocimiento seguro de la sociedad.

Pero esa conjunción, garantía de su éxito, era a la vez su debilidad teórica. Me parece que una de las limitaciones del marxismo fue su imposibilidad de hacer consistentes, en una teoría unificada, su pretensión cientifista y la propuesta ética implícita en su filosofía de la acción.

Pues bien, son esos dos grandes temas del marxismo los que examina, con preferencia, el llamado "marxismo analítico". El libro de Paulette Dieterlen dis-

\footnotetext{
${ }^{1}$ Lucio Coletti, De Rousseau a Lenine. París, L'esprit des lois, 1972, p. 293.
} 
cute, primero, los intentos por salvar al marxismo como teoría científica. El materialismo histórico sería una clase de explicación funcional, que sin compartir los supuestos conservadores del funcionalismo clásico (el de Malinovsky o Parsons), podría dar razón del cambio social. Este tema ha dado lugar a una discusión extremadamente rica. Paulette Dieterlen la presenta con claridad y rigor, discute las distintas alternativas teóricas y contribuye a su solución con una propuesta propia interesante.

La teoría de Marx ofrece dos versiones. En unos textos, el motor de la historia es el aumento de las fuerzas productivas, y la causa del cambio, su choque con las relaciones de producción existentes. En otras versiones, la causa principal de todo cambio histórico es la lucha de clases. En la primera interpretación, la causa principal reside en la tecnología, en la segunda, en la acción política de un sujeto colectivo. La propuesta de Paulette Dieterlen pretende unir ambos principios en un solo modelo teórico de explicación. Así, se trata de hacer compatibles, en la teoría de Marx, el principio "tecnológico" de las fuerzas productivas, con el "político" de la lucha de clases. Pero, para ello, tiene que introducir las intenciones colectivas en el modelo explicativo. Lo cual nos conduce al segundo tema.

La teoría de Marx es también una filosofía de la praxis social. Remite, por lo tanto, a las intenciones y creencias de los agentes. La autora del libro examina entonces la teoría marxista a la luz de las llamadas "explicaciones intencionales", es decir, las que intentan dar razón de las acciones por sus deseos, creencias y fines. Se plantea aquí un problema central del marxismo: la motivación para la acción revolucionaria. ¿Por qué el proletariado buscaría la revolución antes que la simple mejoría económica? ¿No es éste el problema que, en la literatura marxista, enfrentó las tesis de Lenin y Rosa Luxemburgo a las de los reformistas? El problema al que los marxistas dedicaron tantas polémicas, depurado, desinfectado de compromisos políticos, se presenta ahora en otro registro: como un problema puramente teórico de explicación de la acción en favor de un bien común. Ha perdido la fuerza de la pasión, ha ganado la fría claridad de la razón. Hemos dejado de actuar, ahora sólo tratamos de comprender. El punto no es ya ¿cómo actuar para liberarnos?, ¿reforma o revolución?, sino ¿cómo explicar que actuemos para liberarnos?, ¿qué motiva que podamos elegir entre reforma y revolución? La discusión no prescribe vías de acción -como en la vieja polémica marxista- pero es iluminadora para comprender el problema central de la acción colectiva dirigida a un bien común, no sólo en el marxismo sino en cualquier teoría de la acción. Dieterlen propone un esquema explicativo que modifica el de otros autores. Su ventaja, frente a ellos, es importante. Podría resumirla en dos puntos: 1) Incluir los actos intencionales y el cambio de creencias, dentro de una explicación funcional; 2) explicar el cambio de creencias por la teoría de la 
ideología de Marx. Se trata de una contribución significativa para unir en una sola teoría varios conceptos que en Marx no siempre aparecen claramente relacionados.

Pero también tiene otra implicación que a mí me interesaría destacar. A mi juicio, la falla principal del "marxismo-leninismo" fue su cientificismo, en cuyo nombre pasó a segundo término la dimensión ética del mensaje socialista, con todas las consecuencias trágicas, en la práctica de los regímenes comunistas. $\mathrm{Si}$ queremos recuperar el valor de la propuesta socialista, habrá que fundarlo de nuevo en una ética concreta, social, que supere las morales individualistas del pensamiento moderno. Esta dimensión ética constituye para mí el núcleo más valioso del marxismo; fue ocultada por su obsesión de ser una ciencia, y sólo podrá recuperarse cuando se libere de esa máscara. Creo que la discusión de Paulette Dieterlen, continuando la de otros autores del "marxismo analítico", abre una ventana para plantear de nuevo la recuperación ética del marxismo. Y Paulette Dieterlen no deja de sugerirlo al final de su libro.

Entre nosotros, ese libro puede contribuir a desbaratar inveterados prejuicios que obstaculizaron un acercamiento entre la filosofia marxista y otras corrientes del pensamiento contemporáneo. La discusión entre ellas podía ser de gran fruto. Por una parte, los autores de que trata este libro se han reducido a discutir algunas tesis del propio Marx, sin referirse a sus desarrollos posteriores. Sería muy útil considerar, dentro de los problemas tratados, las aportaciones de otros autores marxistas. Doy sólo un par de ejemplos: la interpretación del materialismo histórico como una explicación funcional, ganaría en complejidad si se le contrapone la lectura "estructuralista" de Marx, realizada por Althusser y Balibar; la explicación de las motivaciones de la acción de clases sociales se afinaría si, en lugar de atenerse sólo a autores como Elster o Davidson, recordara algunos análisis de Lukács o de Gramsci; ¿y cómo prescindir de Ernst Bloch o aún del "austromarxismo" en la discusión de la posibilidad de una acción intencional colectiva con una dimensión moral? Paulette Dieterlen no pudo emprender una nueva lectura de esos autores marxistas a la luz de los temas discutidos por el "marxismo analítico"; para ello hubiera tenido que escribir otro libro. Pero es una tarea abierta para nuevo trabajos, que podrían enriquecer los planteamientos a que llega el suyo.

Por su parte, quienes se hayan formado en el marxismo o se hayan dedicado años a su estudio, se verían beneficiados por su acercamiento a estos nuevos enfoques. Ellos abren la vía para poner en relación el pensamiento marxista con logros indudables de la filosofía de la ciencia y de la teoría de la acción contemporáneas, de los que el "marxismo-leninismo" estuvo alejado, por motivos más ideológicos que filosóficos.

Quien quiera renovar un pensamiento socialista tendrá que hacerlo con una reflexión nueva, que rompa con las exclusiones y los prejuicios intelectuales 
antiguos. Y un estímulo para ese nuevo pensamiento puede estar en esta confluencia inicial entre las viejas, pero sólidas, teorías de Marx y el rigor crítico del pensamiento analítico. 